\title{
Use of Fillers for Optimal Formulation of Self-Compacting Concretes
}

\author{
Abdelhamid Noufid ${ }^{\mathrm{a}^{*}}$, Sougrati Belattar ${ }^{\mathrm{b}}$ \\ ${ }^{a}$ Ph.D.Student, Faculty of Science Semlalia, Cadi Ayyad University, Marrakech, Morocco. \\ ${ }^{b}$ Professor, Faculty of Science Semlalia, Cadi Ayyad University, Marrakech, Morocco. \\ Received 06 January 2018; Accepted 02 February 2018
}

\begin{abstract}
The objective of this study is to achieve an optimal formulation of self-compacting concrete using local materials from the country of Morocco, the use of this type of concrete remains very limited compared to a concrete vibrated in this country, due to lack mastery by companies. We will therefore try to study an optimal formulation that respects European standards and gives comparable results, even improved, to those of vibrated concrete, in order to be able to replace vibrated concrete with self-compacting concrete in construction sites. Thus, SCC mixtures containing amounts of fillers were examined, and with different Portland cement dosages: $350 ; 375$ and $400 \mathrm{~kg} / \mathrm{m}^{3}$. The method of formulation is made in accordance with French regulations. The results obtained were compared to these vibrated concrete counterparts containing the same cement dosages. Tests include compression, traction and flexion tests at 3, 7 and 28 days of age. Several studies have been carried out internationally, but at the national level, there is no study to this effect. The results obtained show that there is an improvement in the strength of concrete, in addition to the liquid appearance of concrete. It is this last aspect that characterizes the SCC, which allows it a flow in the areas inaccessible by the vibrator, thus saving time and performance of the structure to achieve.
\end{abstract}

Keywords: Self-Compacting Concrete; Formuation; Fillers; Resistance.

\section{Introduction}

Self-consolidating concretes (SCCs), which have been developed over the past three decades by Japanese researchers [1], are still referred to as "new concretes" because their use remains modest, although they have a high potential for development. The specificity of SCC compared to traditional concretes lies in the fact that they are extremely fluid and don't require vibration to be implemented. Compacting under their own weight, they can be cast in very scrapped areas or in areas of complex architecture and difficult to access [2].Their origin seems to stem from the need to use materials that are more and more "efficient" to offset a reduction in the quality of constructions due to a bad Placement of the material [3]. The use of a traditional concrete requires a vibration phase in order to properly fill the formwork. This step determines the quality of the final structure, but it is also a laborious task that requires special know-how. The solution proposed was to use a very fluid material capable of compacting under its own weight without external vibration. One of the main advantages of the SCC is that it allows the production of high-quality facings; also, it has an excellent deformability and high resistance to segregation [4-5]. SCCs are formulated differently from ordinary concretes: they contain less gravel, more fine elements and fluidifiers. This is of course what gives them an auto-compacting character. However, it is also likely that these results in a different mechanical behavior compared to ordinary concretes.

* Corresponding author: abdelhamid.noufid@ced.uca.ac.ma

\section{doi) http://dx.doi.org/10.28991/cej-030969}

> This is an open access article under the CC-BY license (https://creativecommons.org/licenses/by/4.0/).

(C) Authors retain all copyrights. 
In this research, we will study mixtures of self-compacting concrete, at first we will try to find an optimal and adequate formulation, and in a second time we will compare the mechanical tests of this formulation with those of an ordinary concrete, more particularly the compressive strengths at the age of 3, 7 and 28 days. In the first step, the research concerns the formulation; that is to say, find the dosage of the different components, namely, the gravel, the sand, the cement, the fillers and the water. The mixtures studied are from MX1 to MX9, which are grouped by dosage of Portland cement, the first group of MX1 to MX3, are dosed at $350 \mathrm{Kg} / \mathrm{m}^{3}$, the second group of MX4 to MX6, are dosed at $375 \mathrm{Kg} / \mathrm{m}^{3}$ and the third group from MX7 to MX9, are dosed at $400 \mathrm{Kg} / \mathrm{m}^{3}$. These mixtures are subject to preliminary tests, namely the Abrams cone collapse test, the LBOX box flow test and the sieving stability test. These tests are carried out according to European standards, and according to the results of these tests, we will discard mixtures that do not meet the specifications of the standards. The mixtures that pass these tests will be subject to a second measurement campaign, these are the tests of compressive and tensile strengths at different ages of 3,7 and 28 days. In a second step, these self-compacting concrete mixtures with vibrated concrete counterparts will be compared in terms of compressive strength. From these results, we can judge the use of self-healing concrete as an alternative of vibrated concrete in Moroccan construction sites.

\section{Principal Characteristics Of Self-Compacting Concrete}

\subsection{Principle}

The main difference between a SCC and a traditional concrete (TC) is the behavior of the material in the fresh state and therefore in its implementation, the specificity of a SCC is to be extremely fluid. It compacts under the effect of its own weight and therefore doesn't require vibration to be set up. Furthermore, the material must be stable to ensure the homogeneity of the final structure. In terms of implementation, SCCs offer more flexible conditions than traditional concrete due to the suppression of vibration [6]. One of the major advantages of SCCs is the reduction of the duration of the casting phase: the emptying of the bucket takes place more quickly, the flow of the material is obviously easier, the vibration phase is suppressed and the upper is easier to achieve. In general, SCCs have the same cement dosage and therefore it is mainly the addition of an addition, in water only the TC, as well as a volume of sand quite close [2]. The role of the paste is to separate the gravel to limit the contacts. The large volume of fine elements also guarantees the compromise between stability and maneuverability [6].

\subsection{Characteristics in Fresh State}

\subsubsection{Workability}

Workability characterizes the capacity of concrete to flow under its own weight:

- Possibility of casting heavily scraped areas,

- Possibility of casting areas of complex architecture and difficult to access,

- Obtaining very good siding qualities.

The reference test for characterizing the workability of SCCs is: Abrams Cone Spread Test [7]: The conventional Abrams cone test is used to measure spreading. It therefore gives an indication of its capacity to self-compact in an unconfined environment. This cone is placed on a plasterboard having a clean, moistened surface and of sufficient size, then it is filled with concrete the cone is lifted and the concrete emerges therefrom forming a wafer which widens under its own energy without the need to raise and drop the plate as in the conventional spreading test. The spreading value corresponds to the average diameter of the concrete cake thus obtained, which should be between 600 and $800 \mathrm{~mm}$ [2].

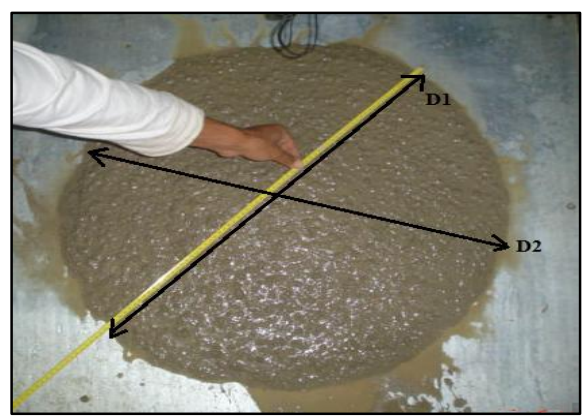

Figure 1. Slump flow test for self-compacting concrete

\subsubsection{Homogeneity}

Once the filling has been completed, the material must flow and pass through more or less dense frames. To realize this property, various tests are available to highlight the capacity of a SCC to flow through reinforcement more or less 
dense. If the aggregates are blocked and arched at the reinforcement bars, the filling of the formwork will not be done properly. The reference test to characterize this property is: L-box test [8].

It is possible to test the mobility of the concrete in a confined environment. During the test, the vertical part of a Lshaped box is first filled. After one minute, the trap is lifted allowing the flow through three reinforcements. The final filling rate $\mathrm{H} 2$ / H1 indicates the mobility of the concrete in a confined medium must be greater than 0.8 [2]. A bad flow of the concrete through the reinforcement informs us of a problem of blocking or segregation.

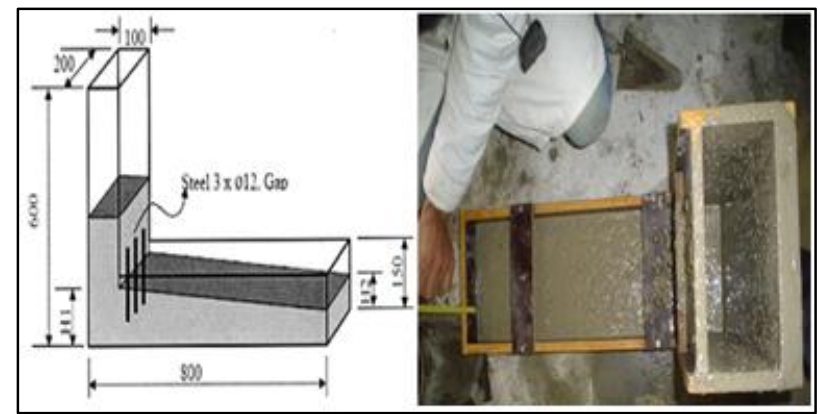

Figure 2. L-box test

A second test also allows judging the homogeneity of the concrete is the test of stability to the sieve; it makes to judge the possibility of segregation of the concrete. At the end of the mixing, ten liters of concrete are poured into a tray. After a waiting period of fifteen minutes, a mass of $4.8 \mathrm{~kg}$ of concrete is poured from the tray on to a sieve of 5 $\mathrm{mm}$ mesh [2]. Two minutes later, the quantity of paste that had passed through the sieve was weighed. A high percentage of milt relative to the initial mass is an indicator of low resistance to segregation.

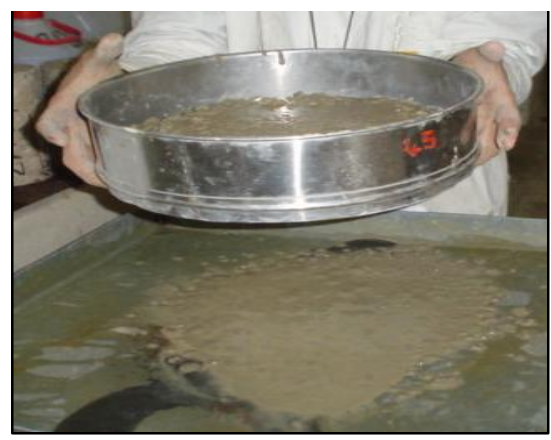

Figure 3. Sieve stability test

\subsection{Formulation of Self-Compacting Concrete}

To formulate ordinary concretes, the most widely used method in the industry is the modified Dreux-Gorisse method [9]. It proposes different charts to estimate the water and cement dosages in order to obtain the desired strength and sag. The development of a SCC formulation is much more complex, in addition to the cone test, the Lbox test and the sieve stability test The characteristics of SCCs; A concrete rich in a fluid paste is very sensitive to segregation. The different studies carried out made it possible to put forward a simple principle of formulation for the SCC: it is necessary to reduce the inter-granular friction at the different scales (cement, sand and aggregate). Thus, the volume of the paste must be increased to the detriment of gravette [10-11]. Thus, the volume of paste must be increased. However, SCCs must have a low flow threshold so that the flow begins rapidly and their viscosity has to be moderate in order to limit the flow time. That is why the volume of paste in a SCC represents 35 to $45 \%$ of the total volume, whereas in traditional concrete it is 20 to $35 \%$ and a superplasticizer is used to thin the paste. Other parameters must also be taken into consideration such as:

- Maximum aggregate diameter $\left(\mathrm{D}_{\max }\right)$ : It appears that the risk of blocking, for a given reinforcement, increases when the maximum diameter of the aggregates increases. In order to limit the risk of blockage, the maximum diameter of the aggregates must therefore be reduced compared to that of a traditional concrete. The maximum diameter of the chippings is between 10 and $20 \mathrm{~mm}$ [2]. The choice of a larger maximum diameter is possible but is justified only when confinement and density of reinforcement are low.

- Volume of large aggregates: The quantity of large aggregates has a strong influence on the ability of concrete to pass through reinforcements. The smaller the aggregate, the higher the filling capacity. However, the gravel increases the granular compactness of the skeleton, which makes it possible to limit the quantity of binder necessary to obtain the desired rheological and mechanical characteristics. It is therefore a question of finding a compromise during the formulation of the material. The quantity of aggregates must be reduced to limit the risk of 
blockage. As a result, the quantity of suspending material is increased. But the quantity of sand contained in the mortar should not be too great since this increases the flow resistance and viscosity. In the case of SCCs, the maximum diameter of the aggregates is limited (on the order of 16 to $20 \mathrm{~mm}$ ) [2].

- Role of superplasticizers: superplasticizers are used widely to produce flowable, strong, and durable Portland cement concretes and mortars [12]. The hydration behaviors of Portland cement in the presence of superplasticizers have been investigated by a number of researchers [13-16]. It is thus possible to manufacture very fluid concretes, even with less water than is necessary to hydrate the cement, and thus to make concretes with a low Water / Cement ratio that are easy to install. The time of introduction of the superplasticizer during kneading plays a role in the saturation dosage. If the introduction is delayed, the saturation dosage is lower; it is obtained for a smaller quantity of superplasticizer. Thus, delaying its introduction allows the superplasticizer to be more efficient and to obtain mixtures more fluid than if it had been introduced at the beginning of mixing.

- Role of fines: Superplasticizers therefore make it possible to obtain very fluid concretes by reducing the friction between cement grains and by releasing a certain quantity of water. Their use is not sufficient in the case of SCCs. Interactions between larger grains must also be reduced. In order to increase the quantity of paste of a SCC, it is then possible to envisage increasing the quantity of cement [17]. However, this would lead to a significant increase in the cost of the material but also to problems of shrinkage due to the rise in temperature during the hydration of the cement. It is therefore necessary to replace part of the cement with mineral additions. Different additions are cited in the literature [18]: fly ash, blast furnace slag, silica fume and calcareous filler. These materials can have a chemical influence and / or a physical role depending on their nature.

SCCs are formulated with a higher volume of paste and sand / gravel ratio than in vibrated concrete. Moreover, they generally contain large quantities of adjuvants.

\section{Experimental study}

\subsection{Materials}

The materials used in this study come from the following quarries:

- Gravette G1 and Grain de Riz from Oued CHERRAT/Morocco of limestone nature;

- Crushed sand from the quarry Ouled ABBOU/Morocco of dolomite nature (SC);

- Sand dune from the town of KENITRA/Morocco of siliceous nature (SM);

- Mixing water is the drinking water of the network.

The different aggregates were subjected to a laboratory characterization; Table 1. summarizes the results. Figure 4. schematizes the curves of the particle size analysis performed on the concrete formulation materials. There is clearly continuity between the three curves, in other words an overlap zone between these curves, and subsequently the matrix contains the various dimensions from the finest to the largest elements, therefore a texture of the concrete and a consistent appearance.

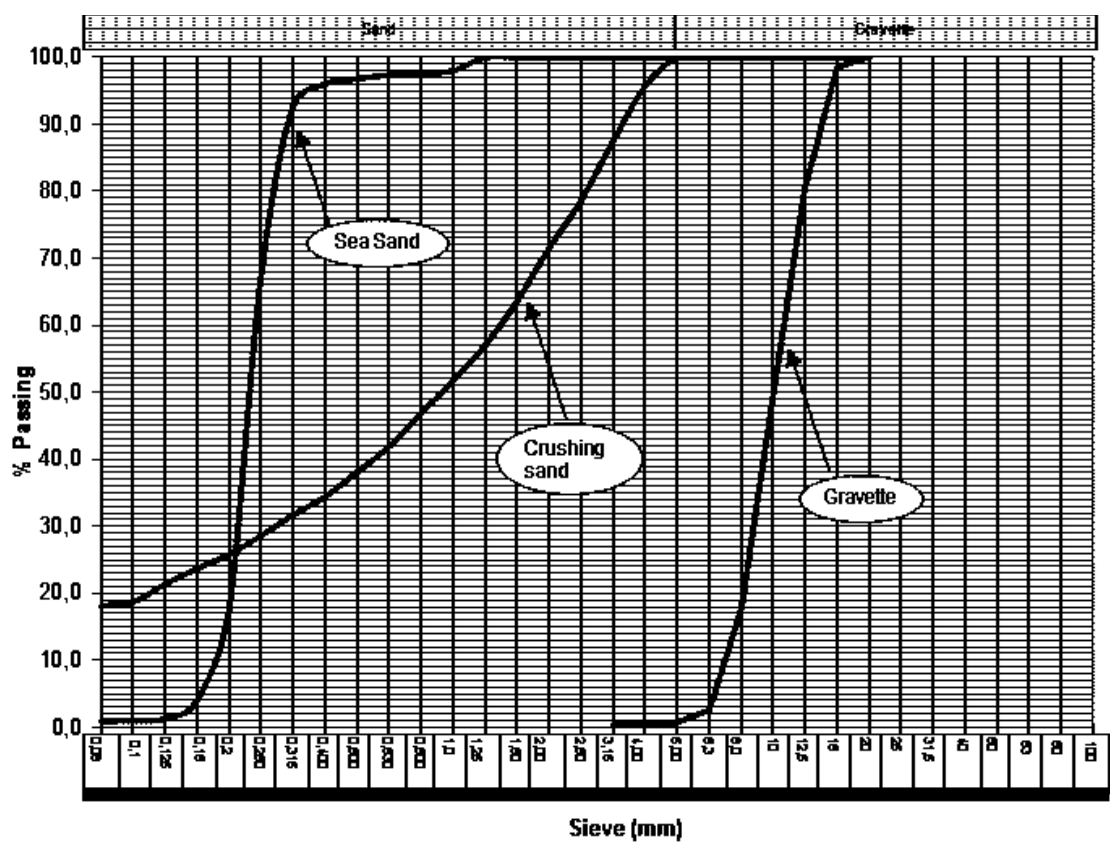

Figure 4. Curves of granulometric analyzes of aggregates 
Table 1. Identification tests on aggregates

\begin{tabular}{|c|c|c|c|}
\hline Nature of material & Gravette & SC & SM \\
\hline Particle size analysis NM 10.1.700 [19] & \multicolumn{3}{|c|}{ See the chart above } \\
\hline Coefficient of flattening A(\%) NM 10.1.155 [20] & 15 & - & - \\
\hline Actual density of gravel $\rho r\left(\mathrm{t} / \mathrm{m}^{3}\right) \mathrm{NM} 10.1 .146$ [21] & 2.67 & - & - \\
\hline Gravel absorption coefficient Ab (\%) NM 10.1.146 [21] & 0.9 & - & - \\
\hline Porosity of Gravette (\%) NM 10.1.146 [21] & 2.4 & - & - \\
\hline Actual sand density $\rho r\left(t / \mathrm{m}^{3}\right) \mathrm{NM} 10.1 .149$ [22] & - & 2.62 & 2.60 \\
\hline Sand absorption coefficient Ab (\%) NM 10.1.149 [22] & - & 0.2 & 0.3 \\
\hline Surface cleanliness P (\%) NM 10.1.169 [23] & 0.4 & - & - \\
\hline Equivalent of Sand SE (\%) NM 10.1.147 [24] & - & 63 & 89 \\
\hline Los Angeles coefficient LA (\%) NM 10.1.138 [25] & 23 & - & - \\
\hline
\end{tabular}

\subsection{Research Methodology}

The main objective of this study is to identify the various parameters related to the composition of concrete. The formulations adopted at a first level were deduced by the application of the general formulation recommendations referred to in the report of section 2, namely:

- Percentage of gravels between 28 and 35\% relative to the total volume of the mixture.

- Determination of fine elements (cement + fine elements) between 400 and $600 \mathrm{~kg} / \mathrm{m}^{3}$, vary the cement dosage between 350 and $400 \mathrm{~kg} / \mathrm{m}^{3}$.

- The rest of the fine elements $(<80 \mu \mathrm{m})$ comes from the fine fraction of the crushing sand used.

- Volume of water less than $200 \mathrm{~L} / \mathrm{m}^{3}$ to be adjusted according to the required rheological characteristics of the concrete. It should be noted that this volume must take into account the water content of the different aggregates and their absorption coefficient.

- The remainder of the volume is completed by sand.

The studied mixes are shown in the Table 2.

Table 2. Self-compacting concrete mixtures studied

\begin{tabular}{|c|c|c|c|c|c|c|c|c|c|}
\hline Mixes & MX1 & MX2 & MX3 & MX4 & MX5 & MX6 & MX7 & MX8 & MX9 \\
\hline Cement $350 \mathrm{Kg} / \mathrm{m}^{3}$ & $\mathrm{X}$ & $\mathrm{X}$ & $\mathrm{X}$ & & & & & & \\
\hline Cement $375 \mathrm{Kg} / \mathrm{m}^{3}$ & & & & $\mathrm{X}$ & $\mathrm{X}$ & $\mathrm{X}$ & & & \\
\hline Cement $400 \mathrm{Kg} / \mathrm{m}^{3}$ & & & & & & & $\mathrm{X}$ & $\mathrm{X}$ & $\mathrm{X}$ \\
\hline Water $100 \mathrm{l} / \mathrm{m}^{3}$ & $\mathrm{X}$ & & & $\mathrm{X}$ & & & $\mathrm{X}$ & & \\
\hline Water $150 \mathrm{l} / \mathrm{m}^{3}$ & & $\mathrm{X}$ & & & $\mathrm{X}$ & & & $\mathrm{X}$ & \\
\hline Water $200 \mathrm{l} / \mathrm{m}^{3}$ & & & $\mathrm{X}$ & & & $\mathrm{X}$ & & & $\mathrm{X}$ \\
\hline
\end{tabular}

\subsubsection{Different Stages of the Experimental Study and Spefications}

Starting from a ratio G / S (mass of gravette to mass of sand) close to one, the dosage was varied in fine elements by adopting the following parameters:

- The volume of paste varies between 327 and $350 \mathrm{~L} / \mathrm{m}^{3}$.

- The cement mass varies between 350 and $400 \mathrm{~kg} / \mathrm{m}^{3}$, while the fines are obtained by sand fines of 50,100 and $150 \mathrm{~kg} / \mathrm{m}^{3}$. The total mass of the fines thus obtained in the mixture varies between 400 and $500 \mathrm{~kg} / \mathrm{m}^{3}$.

- The specifications to be satisfied are as follows: the specifications to be satisfied are grouped in Table 3 .

Table 3. Fresh concrete specifications

\begin{tabular}{ccc}
\hline Characteristic & Min & Max \\
\hline Slump flow (mm) [2] & 600 & 800 \\
L-Box (ratio) [11] & 0.8 & 1 \\
Sieve Stability (\%) [2] & 5 & 15 \\
\hline
\end{tabular}

The mixtures thus obtained are given in Table 4. 
Table 4. Preliminary formulation of self-compacting concrete

\begin{tabular}{cccccccccc}
\hline Mixes & MX1 & MX2 & MX3 & MX4 & MX5 & MX6 & MX7 & MX8 & MX9 \\
\hline Cement & & 350 & & & 375 & & & 400 & \\
Fillers & 50 & 102 & 151 & 101 & 151 & 49 & 101 & 148 & 81 \\
Total fine elements & 400 & 452 & 501 & 476 & 526 & 424 & 501 & 548 & 481 \\
Aggregate (G) & 873 & 860 & 833 & 846 & 828 & 894 & 838 & 817 & 868 \\
$\quad$ Sand & 874 & 874 & 837 & 892 & 834 & 950 & 879 & 826 & 898 \\
Distribution of sand: & & & & & & & & & \\
Sand of dune & 600 & 312 & 2 & 332 & 1 & 677 & 319 & 8 & 453 \\
Crushing sand & 274 & 562 & 835 & 561 & 834 & 273 & 560 & 818 & 445 \\
$\quad$ Water & 195 & 180 & 185 & 170 & 180 & 150 & 170 & 180 & 160 \\
Ratio Gravette/aggregate & 0.50 & 0.50 & 0.50 & 0.49 & 0.50 & 0.48 & 0.49 & 0.50 & 0.49 \\
Report G/S & 1.00 & 0.98 & 1.00 & 0.95 & 0.99 & 0.94 & 0.95 & 0.99 & 0.97 \\
\hline
\end{tabular}

A) Optimization of the quantity of paste

The formulation method based on the optimization of the quantity of paste i.e. to find the minimum quantity of paste which will allow us to avoid blockages during the flow, and therefore to ensure the maneuverability of the mixture. Thus, for the same cement dosage, several tests were carried out to obtain the optimum quantity of the fines and the adjuvant dosage as shown in Table 4.

Table 5. Optimization of the quantity of paste

\begin{tabular}{|c|c|c|c|}
\hline Mixture & Observations & Preliminary conclusions & Continuation of the study \\
\hline MX1 & $\begin{array}{ll}\rightarrow & \text { Low spreading :D=490 mm } \\
\rightarrow & \text { LBOX : Blocking of aggregates } \\
\rightarrow & \text { Sieve stability : } 2 \%\end{array}$ & Low paste volume & Test the Mix MX3 \\
\hline MX3 & $\begin{array}{l}\rightarrow \quad \text { Acceptable spread } \mathrm{D}=610 \mathrm{~mm} \\
\rightarrow \quad \text { Vault formation at armature level } \\
\rightarrow \quad \text { Paste too viscous }\end{array}$ & $\begin{array}{l}\text { The aggregates appear to } \\
\text { be trapped in the paste. } \\
\text { Increase the adjuvant } \\
\text { dosage }\end{array}$ & $\begin{array}{c}\text { Testing again MX1 and MX3 } \\
\text { with a stronger adjuvant } \\
\text { dosage } 1.5 \%, 1.8 \% \text { and } 2 \%\end{array}$ \\
\hline MX1 & $\begin{array}{l}\rightarrow \quad \text { Spreading : D=420 mm } \\
\rightarrow \quad \text { L-Box ; Blocking of aggregates } \\
\rightarrow \quad \text { Sieve stability : } 1.6 \%\end{array}$ & $\begin{array}{l}\text { Same conclusion as in the } \\
\text { first MX1 test }\end{array}$ & Test MX3 \\
\hline MX3 & $\begin{array}{l}\rightarrow \quad \text { Spreading } \mathrm{D}=660 \mathrm{~mm} \\
\rightarrow \quad \text { Flow more freely but still insufficient } \\
\\
\mathrm{H} 2 / \mathrm{H} 1=0.5 \\
\rightarrow \quad \text { Sieve stability } 8,8 \%\end{array}$ & $\begin{array}{l}\text { Despite a higher level of } \\
\text { adjuvant, the aggregates } \\
\text { don't seem to be released } \\
\text { from the too viscous paste }\end{array}$ & $\begin{array}{l}\text { Test an intermediate mixture } \\
\text { MX2 }\end{array}$ \\
\hline MX2 & $\begin{array}{ll}\rightarrow & \text { Spreading D }=730 \mathrm{~mm} \\
\rightarrow & \text { L-Box : Absence of aggregate blocking } \\
& (\mathrm{H} 2 / \mathrm{H} 1=1) \\
\rightarrow \quad & \text { Sieve stability : } 20 \%\end{array}$ & Segregation Phenomenon & $\begin{array}{l}\text { Reduce the quantity of water } \\
\text { and / or adjuvant }\end{array}$ \\
\hline
\end{tabular}

Thus, it is deduced that the best mixture of rheological behavior of a SCC is that obtained from a mixture MX2 comprising approximately $100 \mathrm{~kg}$ of calcareous fines. This conclusion was verified for the other cement measurements.

B) Skeletal optimization

The formulation of the SCCs is also based on an optimization of the granular skeleton. Thus, one of the most important parameters to study was the Gravette / Aggregate Total (G / GT) ratio or the Gravette/Sand (G / S) ratio. Table 5. presents the different experiments carried out.

Table 6. Optimization of the granular skeleton

\begin{tabular}{|c|c|c|c|}
\hline Reports studied & Phenomenon observed & Preliminary Findings & Continuation of the study \\
\hline $\mathrm{G} / \mathrm{GT}=0.50$ & $\begin{array}{ll}\rightarrow & \text { Spreading : D }=650 \mathrm{~mm} \\
\rightarrow & \text { L-BOX : H2 / H1 = } 0.3 \\
\rightarrow & \text { Sieve stability : } 8 \%\end{array}$ & $\begin{array}{l}\text { Difficulty of the concrete } \\
\text { to pass between the } \\
\text { reinforcements }\end{array}$ & Reduce G / GT Report \\
\hline $\mathrm{G} / \mathrm{GT}=0.48$ & $\begin{array}{ll}\rightarrow & \text { Spreading }: \mathrm{D}=710 \mathrm{~mm} \\
\rightarrow & \text { L-BOX }: \mathrm{H} 2 / \mathrm{H} 1=0.8 \\
& \rightarrow \quad \text { Sieve stability : } 12 \%\end{array}$ & $\begin{array}{l}\text { Good appearance of fresh } \\
\text { concrete }\end{array}$ & Reduce again G / GT \\
\hline $\mathrm{G} / \mathrm{GT}=0.45$ & $\begin{array}{l}\rightarrow \quad \text { Spreading : D=700 mm } \\
\rightarrow \quad \text { LBOX : H } 2 / \mathrm{H} 1=0.8 \\
\rightarrow \quad \text { Sieve stability : } 12 \%\end{array}$ & $\begin{array}{l}\text { Good appearance of fresh } \\
\text { concrete }\end{array}$ & Reduce again G / GT \\
\hline $\mathrm{G} / \mathrm{GT}=0.42$ & $\begin{array}{l}\rightarrow \quad \text { Spreading : D }=610 \mathrm{~mm} \\
\rightarrow \quad \text { Vault formation at armature level } \\
\rightarrow \quad \text { Paste too viscous }\end{array}$ & $\begin{array}{l}\text { The aggregates appear to } \\
\text { be trapped in the paste }\end{array}$ & Limit G / GT to 0.45 \\
\hline
\end{tabular}




\subsubsection{Plan of the final mixture}

At the end of these various tests, six formulations were studied. Table 6. shows the mixtures adopted for the rest of the study.

Table 7. Formulations adopted for the study of self-compacting concrete

\begin{tabular}{ccccccc}
\hline Mixes & MX1 & MX2 & MX3 & MX4 & MX5 & MX6 \\
\hline Cement $\left(\mathrm{kg} / \mathrm{m}^{3}\right)$ & 350 & 350 & 375 & 375 & 400 & 400 \\
Total fines+ cement $\left(\mathrm{kg} / \mathrm{m}^{3}\right)$ & 452 & 452 & 476 & 476 & 501 & 501 \\
Sand of dune $\left(\mathrm{kg} / \mathrm{m}^{3}\right)$ & 397 & 347 & 384 & 342 & 388 & 317 \\
Crushing sand $\left(\mathrm{kg} / \mathrm{m}^{3}\right)$ & 562 & 562 & 561 & 561 & 560 & 560 \\
Gravette 6.3/16 $\left(\mathrm{kg} / \mathrm{m}^{3}\right)$ & 788 & 825 & 780 & 822 & 769 & 814 \\
G/GT & 0.45 & 0.48 & 0.45 & 0.48 & 0.45 & 0.48 \\
\hline
\end{tabular}

The quantity of adjuvant was set at $2 \%$ of the cement mass.

\subsection{Results and Discussion}

\subsubsection{Test on SCC}

A) Rheological characteristic on SCC

The various characterization tests on SCC in the fresh state were carried out, these are:

- $\quad$ Spreading at the cone of Abrams,

- $\quad$ L-shaped box (or L-BOX),

- $\quad$ Sieve Stability Test.

The different results obtained are given in Table 7.

Table 8. Results in the fresh state of the various mixtures

\begin{tabular}{ccccccc}
\hline Test & MX1 & MX2 & MX3 & MX4 & MX5 & MX6 \\
\hline Spreading (mm) & 715 & 700 & 660 & 625 & 610 & 665 \\
L-Box & 0.9 & 0.9 & 0.9 & 0.8 & 0.7 & 0.8 \\
Sieve Stability (\%) & 11.6 & 12 & 10.2 & 12.5 & 9 & 12.5 \\
\hline
\end{tabular}

It is then noted that the different results show that the concrete studied exhibits rheological characteristics conforming for a self-compacting concrete with the exception of concrete MX5.

B) Tests on hardened SCC

Figures 5 and 6. show the evolution of the compressive strength and the tensile strength of the different mixtures studied. As regards Figure 5, the various mixtures studied, namely MX1 up to MX6, are represented along the X-axis, and along the y-axis are represented the values of the compressive strengths at the age of 3, 7 and 28 days. According to this figure, the minimum values of compressive strengths correspond to the MX1 mixture, which are 22, 30 and $43 \mathrm{MPa}$ for the three ages, while the maximum values are those found for the MX6 mixture, which are 30, 39 and $56 \mathrm{MPa}$ for the three ages. For Figure 6, the studied mixtures are shown along the $\mathrm{x}$-axis and the results of the tensile strengths at 28 days of age are shown along the y-axis. According to this graph, the maximum resistance is recorded for the mixture MX6 and which is worth $3.6 \mathrm{MPa}$, while the minimum resistance is recorded for the mixture MX3 and which is worth 5.0 MPa. The tests are carried out in accordance with the current standards [26-27]. 


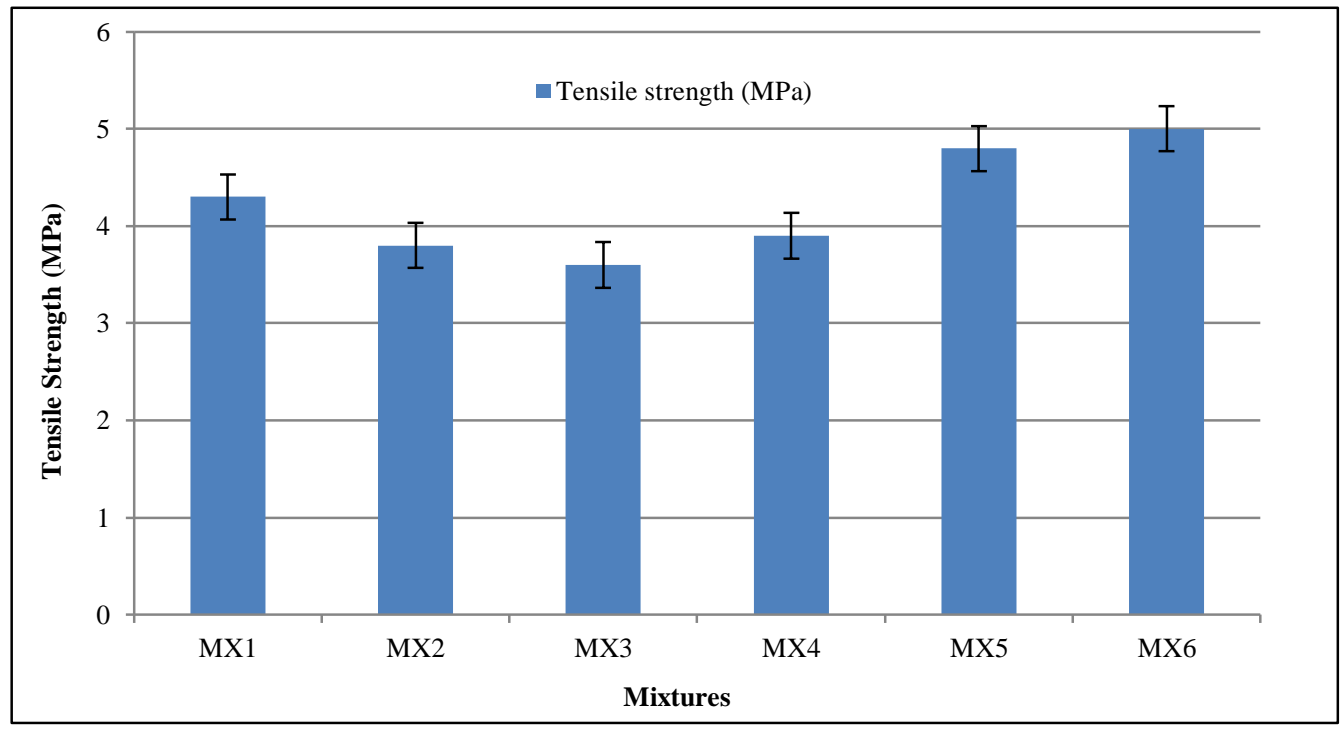

Figure 5. Compressive strength at the age of 3, 7 and 28 days for different SCC mixtures

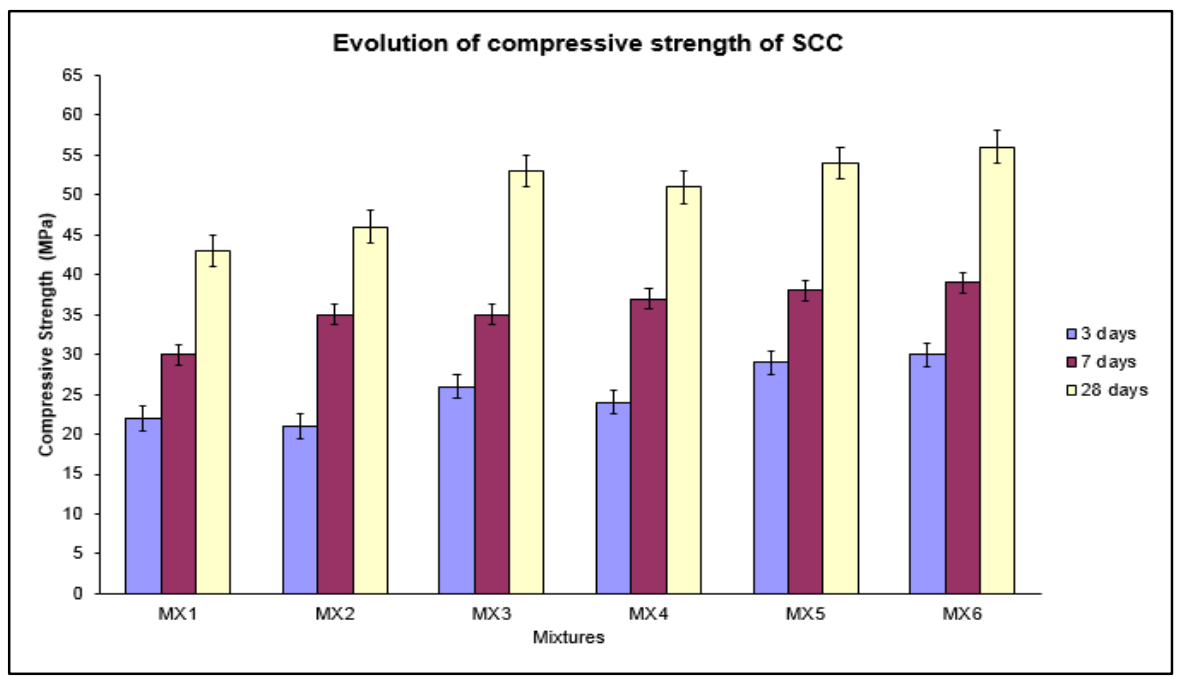

Figure 6. Tensile strength at the age of 28 days for the various mixtures

It is then noted that the compressive strength of the studied mixtures greatly exceed those required by a class B1 concrete in accordance with standard NM 10.1.008 [28] and in all cases exceed $40 \mathrm{MPa}$. It is also noted that the concretes having a ratio G / GT $=0.48$ give slightly higher compressive strengths. The compressive and tensile strength results give values similar to those published by other research carried out on self-placing concrete [29-31].

\subsubsection{Test on Vibrated Concrete}

In order to compare this type of concrete with traditional concretes, we studied three types of vibrated concrete (VC), measured at 350,375 and $400 \mathrm{~kg} / \mathrm{m}^{3}$. In the fresh state, the VC has a slump of $4 \mathrm{~cm}$. Table 8 . shows the mixtures adopted for VC.

Table 9. Formulation of vibrated concrete

\begin{tabular}{cccc}
\hline Type of mixture & VC1 & VC2 & VC3 \\
\hline Gravette 6.3/16 & 1091 & 1075 & 1102 \\
Sand of sea & 261 & 280 & 259 \\
Crushed Sand & 561 & 533 & 510 \\
Cement & 350 & 375 & 400 \\
Water Mixing & 190 & 180 & 185 \\
\hline
\end{tabular}

Figures 7, 8 and 9. show the results of the compression resistances obtained by the two concretes VC and SCC. 


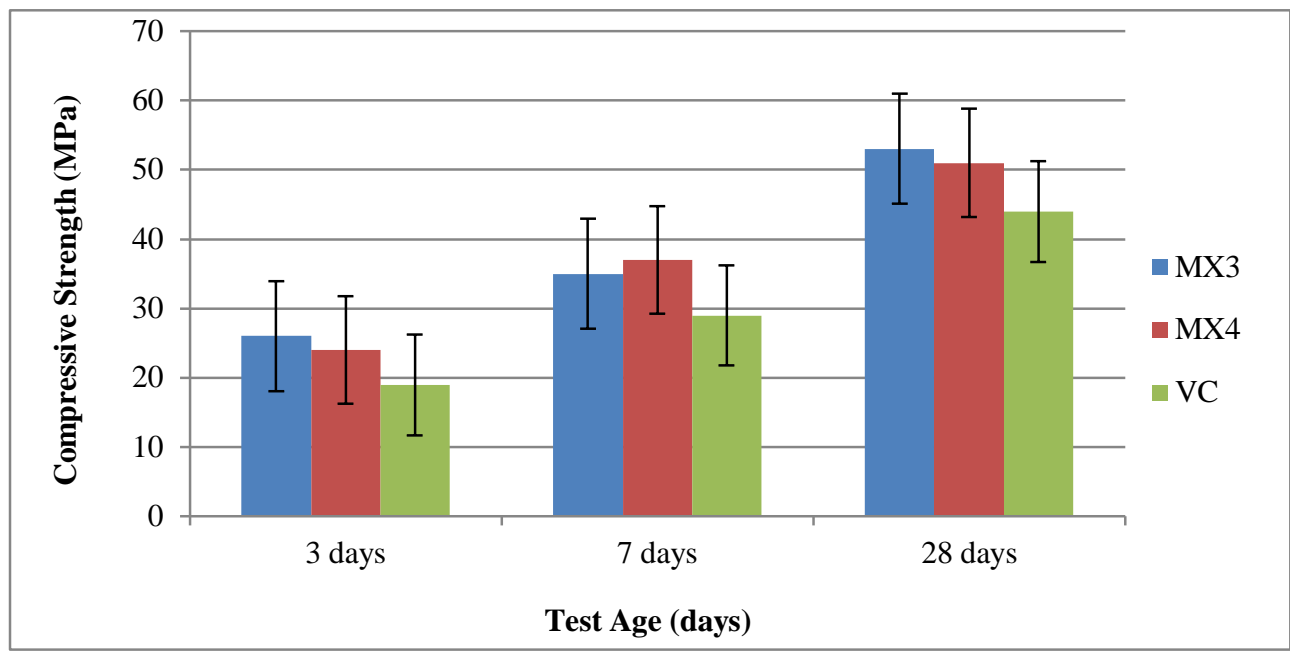

Figure 7. Comparison of compressive strength between SCC and VC for dosing of $350 \mathrm{Kg} / \mathrm{m}^{3}$

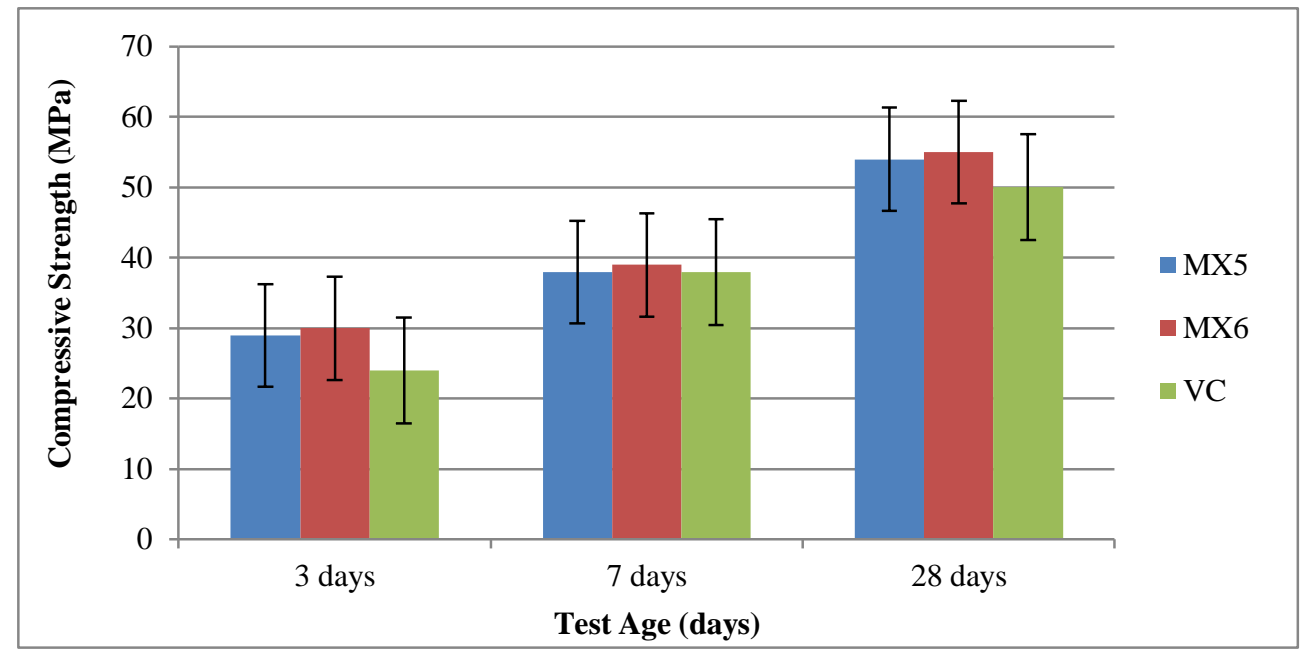

Figure 8. Comparison of compressive strength between SCC and VC for dosing of $375 \mathrm{Kg} / \mathrm{m}^{3}$

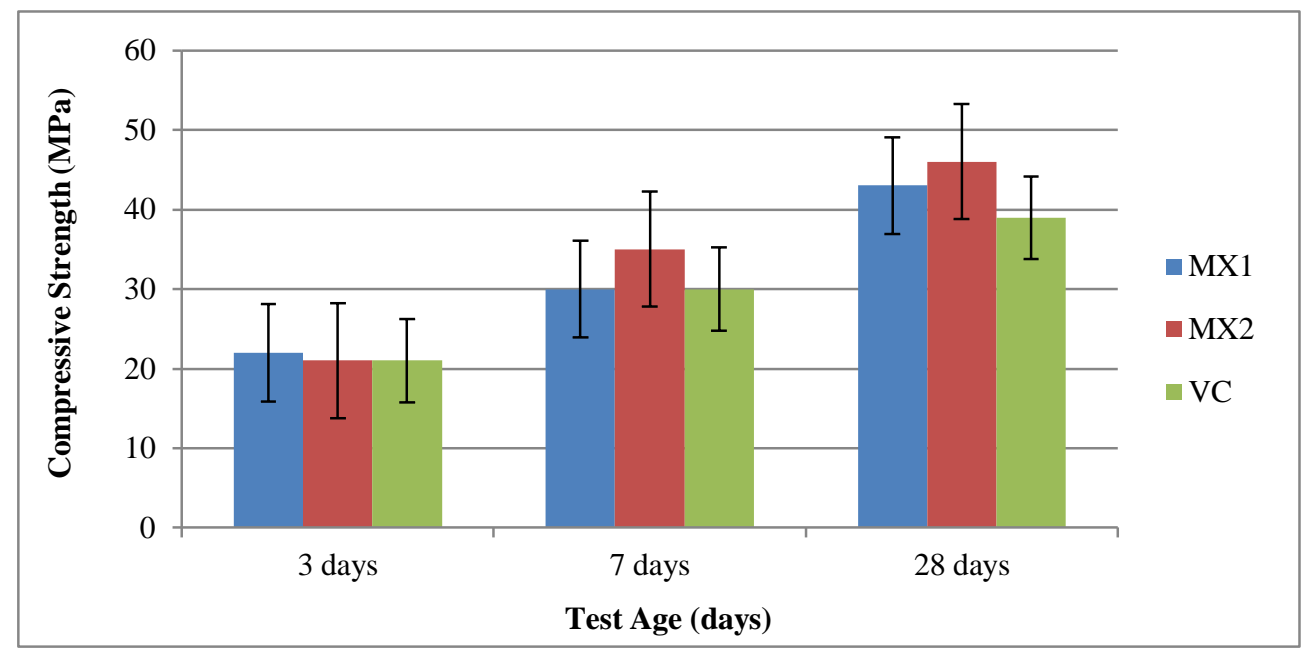

Figure 9. Comparison of compressive strength between SCC and VC for dosing of $400 \mathrm{Kg} / \mathrm{m}^{3}$

Figures 7, 8 and 9. attempt to compare the compression tests at the age of 3, 7 and 28 days of SCC mixtures with those of VC. First, Figure 7. shows the formulations studied with a Portland cement dosage of $350 \mathrm{~kg} / \mathrm{m}^{3}$, it is mixtures MX1 and MX2 for SCC and VC1 for vibrated concrete. According to this figure, there is an improvement of this resistance, which reaches $10 \%$ for MX1 and 18\% for MX2. Secondly, Figure 8. shows this comparison for a Portland cement dosage of $375 \mathrm{~kg} / \mathrm{m}^{3}$. The mixtures relate to MX3 and MX4 for SCC and VC2 for vibrated concrete. There is an improvement of the resistance of SCC compared to VC; this evolution of resistance reaches $20 \%$ for MX3 and $16 \%$ for 
MX4. Finally, Figure 9. also shows an improvement in the resistance of MX5 and MX6 with respect to VC3. The dosage adopted is $400 \mathrm{~kg} / \mathrm{m}^{3}$ of Portland cement, the increase reaches $8 \%$ for MX5 and 10\% for MX6. The results obtained make it possible to conclude that the compressive strengths of the vibrated concretes are lower than the resistances of the self-compacting concretes.

\section{Conclusions}

The experimental study led to a first overview of the various parameters having a direct or indirect impact on the different characteristics of the SCCs. In this context, it is important to note the following findings:

- At the material level, the experiment showed that it is quite possible to produce self-compacting concretes from fired crusher sands.

- With these materials, the dosages of fine elements (Cement + fine elements from crushing sand) are between 450 and $500 \mathrm{~kg} / \mathrm{m}^{3}$ with a G / GT ratio of between 0.45 and 0.48 .

- The tested formulations resulted in a self-compacting concrete with the following characteristics:

- A spreading between 610 and $715 \mathrm{~mm}$;

- An H2 / H1 coefficient at the L-Box between 0.7 and 0.9;

- A Sieve Stability Coefficient of between 9 and $12.5 \%$;

- The compressive and tensile strengths far exceed the characteristic resistances of a Type B1 concrete in the sense of Moroccan Standard NM 10.1.008. They also exceed the resistances obtained by a control vibrated concrete.

\section{References}

[1] Ozawa K., Maekawa K., Kunishima M. and Okamura H. "Performance of Concrete Based on the Durability Design of Concrete Structures". Proceedings of the Second East Asia-Pacific Conf Structural Engineering and Construction, Chiang Mai, Thailand (1989).

[2] EFNARC. "The European Guidelines for Self-Compacting Concrete" (2002).

[3] Agustin, P. Hugas. "Mix Proportion and Properties of Self-Compacting Concrete, Report TVBM-5041, Division of building Materials, Lund Institute of Technology" (1999).

[4] Aslani Farhad. and Nejadi Shami. "Mechanical Properties of Conventional and Self-Compacting Concrete: An Analytical Study." Construction and Building Materials 36 (2012): 330-347. doi: 10.1016/j.conbuildmat.2012.04.034.

[5] Shindoh T., Yokota K. and Yokoi K. "Effect of Mix Constituents on Rheological Properties of Super Workable Concrete." Proceedings of the International RILEM conf, Production Methods and Workability of Concrete, Paisely, Scotland (1996).

[6] Yazicioglu S., Caliskan S., \& Turk K. "Effect of Curing on the Engineering Properties of Self-Concrete." Indian Journal of Engineering \& Materials Sciences 13 (2006): 25-29.

[7] EN 12350-8. "Self Compacting Concrete. Part 8 - Slump Flow Test, European Standard" ( 2010).

[8] EN 12350-10. "Self Compacting Concrete. Part 10 - L Box test, European Standard” (2010).

[9] Dreux G., Gorisse F. and Simonnet J. "Composition des Bétons : Méthode Dreux-Gorisse, Annales de l'Institut Technique du Batiment et des Travaux Publics, France" (1983).

[10] Nagamoto N. and Ozawa K. "Mixture properties of Self-Compacting, High-Performance Concrete.” Proceedings of Third CANMET/ACI International Conferences on Design and Materials and Recent Advances in Concrete Technology, SP-172, V. M. Malhotra, American Concrete Institute, Farmington Hills, Mich (1997).

[11] Khayat K.H. and Ghezal A. "Utility of Statistical models in Proportioning Self-Compacting Concrete.” Proceedings, RILEM International symposium on Self-Compacting Concrete, Stockholm (1999).

[12] Shi Chen, He Ting-shu, Zhang Ge, Wang Xi and Hu Yanyan. "Effects of Superplasticizers on Carbonation Resistance of Concrete." Construction and Building Materials 108 (2016): 48-55. doi : 10.1016/j.conbuildmat.2016.01.037.

[13] Yamada Kazuo, Takahashi Tomoo, Hanehara Shunsuke and Matsuhisa Matsuhisa. "Effects of the Chemical Structure on the Properties of Polycarboxylate-Type Superplasticizer." Cement \& Concrete Researsh, 30 (2000): 197-207. doi: 10.1016/S00088846(99)00230-6.

[14] Kreppelt Fritz, Weibel Martin, Zampini Davide and Romer Micheal. "Influence of solution chemistry on the hydration of polished clinker surfaces - a Study of Different Types of Polycarboxylic Acid-Based Admixtures." Cement \& Concrete Researsh 32 (2002): 187-198. doi: 10.1016/S0008-8846(01)00654-8.

[15] Carazeanu Ionela, Chirila Elisabita and Georgescu Maria. "Investigation of the Hydration Process in 3CaO-Al2O3-CaSO42H2O-Plasticizer-H2O Systems by X-ray Diffraction.” Talanta 57 (2002): 617-623. doi: 10.1016/S0039-9140(02)00100-5.

[16] Yu Yinhui, Liu Jiaping, Ran Qianping, Qiao Min and Zhou Dongliang. "Current Understanding of Comb-Like Copolymer 
Dispersants Impact on the Hydration Characteristics of C3A-Gypsum Suspension.” J. Therm. Anal. Calorim. 111 (2013): $437-444$. doi: 10.1007/s10973-012-2430-3.

[17] Felekoglu Burak. "A comparative Study on the Performance of Sands Rich and Poor in Fines in Self-Compacting Concrete." J. Cons.Bui. Mat. 22 (2008): 646-654. doi: 10.1016/j.conbuildmat.2006.10.007.

[18] Aggarwal P., Siddique R., Aggarwal Y. and Gupta S.M. "Self-Compacting Concrete - Procedure for Mix Design." Leonardo Electronic Journal of Practices and Technologies 12 (2008): 15-24.

[19] NM 10.1.700. "Essais pour Déterminer les Caractéristiques Géométriques des Granulats - Détermination de la Granularité Analyse granulométrique par Tamisage, Morrocan Standards" (2008).

[20] NM 10.1.155. "Granulats - Mesure du coefficient d'aplatissement, Morrocan Standards » (1995).

[21] NM 10.1.146. "Granulats-Mesure des Masses Spécifiques de la Porosité du Poefficient d'Absorption de la Teneur en Eau des Gravillons et Cailloux, Morrocan Standards (1995).

[22] NM 10.1.149. "Granulats-Mesure des Masses Spécifiques, Coefficient d'Absorption et Teneur en Eau des Sables, Morrocan Standards" (1995)

[23] NM 10.1.169, "Granulats-Détermination de la Propreté Puperficielle, Morrocan Standards” (1995).

[24] NM 10.1.147. "Granulats - Equivalent de Sable, Morrocan Standards" (1995).

[25] NM 10.1.138. “Granulats - Essai Los Angeles, Morrocan Standards” (1995).

[26] EN 12390-3. "Testing Harderned Concrete. Part 3 - Compressive Strength of Test Specimens, European Standards” (2002).

[27] EN 12390-5. "Testing harderned concrete. Part 5 - Flexural Strength of test Specimens, European Standards" (2002).

[28] NM 10.1.008. "Béton : Spécifications, Performances, Production et Conformité, Morrocan Standards" (2007).

[29] Ravinder Kaur Sandhu and Rafat Siddique. "Influence of rice husk ash (RHA) on the properties of self-compacting concrete: A review.” J. Cons.Bui. Mat. 153 (2017): 751-764. doi.org/10.1016/j.conbuildmat.2017.07.165.

[30] Stefania Manzi, Claudio Mazzotti and Maria Chiara Bignozzi. "Self-compacting concrete with recycled concrete aggregate: Study of the long-term properties.” J. Cons.Bui. Mat. 157 (2017): 582-590. doi.org/10.1016/j.conbuildmat.2017.09.129.

[31] Miguel C.S. Nepomuceno, L.A. Pereira-de-Oliveira and S.M.R. Lopes. "Methodology for the mix design of self-compacting concrete using different mineral additions in binary blends of powders." J. Cons.Bui. Mat. 64 (2014): 82-94. doi.org/10.1016/j.conbuildmat.2014.04.021. 